\title{
Comparison of Light-emitting Diode and High-pressure Sodium Light Treatments for Hydroponics Growth of Boston Lettuce
}

\author{
Vincent Martineau', Mark Lefsrud ${ }^{2,5}$, and Most Tahera Naznin ${ }^{3}$ \\ Bioresource Engineering Department, McGill University, 21111 Lakeshore, \\ Ste-Anne-de-Bellevue, H9X 3V9, Quebec, Canada
}

\author{
Dean A. Kopsell ${ }^{4}$ \\ Plant Sciences Department, The University of Tennessee, Knoxville, TN \\ 37996
}

Additional index words. HPS, LED, greenhouse, light, energy Lactuca sativa var. capitata, phytochemicals, $\beta$-carotene, chlorophyll a and $b$, neoxanthin, lutein, antheraxanthin, violaxanthin

\begin{abstract}
Recent irradiance level improvements in light-emitting diode (LED) technology has allowed this equipment to compete as suitable replacements to traditional highpressure sodium (HPS) lamps in hydroponics growth environments. The current study compares LED and HPS lighting technologies for supplemental lighting in a greenhouse at HydroSerre Mirabel (Mirabel, Quebec, Canada) for the growth of Boston lettuce (Lactuca sativa var. capitata). The light treatments were applied for 2 hours before sunset and 8.5 hours after sunset to extend the photoperiod to 18 hours. An average total light irradiance (natural and supplemental) of $71.3 \mathrm{~mol} \cdot \mathrm{m}^{-2}$ for HPS and $35.8 \mathrm{~mol} \cdot \mathrm{m}^{-2}$ for LED were recorded over the 4 weeks of each experimental run. Wet and dry biomass of the shoots was recorded. On average, HPS light treatments produced significantly similar shoot biomass compared with LED light treatment, although the LED lamps provided roughly half the amount of supplemental light compared with the HPS lamps during the 4 weeks of the experimental treatment. Analysis of the lettuce samples showed no significant difference in concentrations of $\beta$-carotene, chlorophyll $a$, chlorophyll $b$, neoxanthin, lutein, and antheraxanthin among the light treatments; however, violaxanthin concentrations showed a statistical difference resulting from light treatment. When measured on an energy basis, the LED lamps provide an energy savings of at least $33.8 \%$ and the minimal "regular" HPS provided an energy savings of $77.8 \%$ over the HPS treatment.
\end{abstract}

The vegetable greenhouse industry in Quebec, Canada, was valued at approximately U.S. \$50 million in 1999 with 12 ha dedicated to lettuce, representing $\approx 12 \%$ of the total greenhouse area that year (Carrier, 1999). Greenhouse production expanded greatly in the province in 1987 with the construction of

Received for publication 28 Oct. 2011. Accepted for publication 5 Mar. 2012.

We express our sincere thanks to Dr. Valérie Orsat, McGill, for her valued input. We also extend our gratitude to all of those involved at HydroSerre Mirabel to carry out the experiment in their installations. We also thank Philippe Lefebvre for the use of the LED lamps from his company LED Innovation Design. We also thank Gilles Cadotte, Agr., from CIDES for his advice on many agricultural topics. A special mention goes to Hydro Québec for their financial support, which enabled the experiment to take place.

${ }^{1}$ Graduate Research Assistant.

${ }^{2}$ Assistant Professor.

${ }^{3}$ Postdoctorate Fellow.

${ }^{4}$ Associate Professor.

${ }^{5}$ To whom reprint requests should be addressed; e-mailmark.lefsrud@mcgill.ca.
3.9 ha for tomato (Solanum lycopersicum), cucumber (Cucumis sativus) and pepper (Capsicum annuum) production under artificial lighting (Papadopoulos and Demers, 2000). The current situation for vegetable growers in Canada is challenging because of increased heating costs and costs of supplemental lighting required for year-round production.

The established practice for greenhouse growers interested in supplemental lighting technologies is to install HPS lamps and use them to extend the photoperiod of the crops to increase yields (McAvoy, 1984). However, this practice can be onerous for large installations, both in equipment and energy costs. Some other disadvantages of HPS lamps include heat generation and suboptimal spectrum for photosynthesis. LED lamps are a promising technology that has the potential to improve irradiance efficiency above HPS. Sustained developments in LED technology have brought their irradiance to a suitable level for being considered as a replacement to HPS lamps in hydroponics growth environments. LED lamps are anticipated to replace HPS lamps in most applications as a result of their reduced electricity consumption, improved quality of light, and the possibility for customization of the light spectrum for increased yields (Bourget, 2008; Morrow, 2008; Tennessen et al., 1994). Although equipment costs are still high, as is the case with most new technologies, growers across the world stand to substantially decrease their energy use, which directly translates into reduced costs for the greenhouse growers and reduced carbon emissions from the energy standpoint.

Earlier research reported that changes in irradiance wavelengths can result in changes in biomass production and morphology of plants because of changes in the ratio of the red/far-red spectrum (Brown et al., 1995; Heraut-Bron et al., 2001; Hoenecke et al., 1992; Taiz and Zeiger, 1998) and the effect of blue light (Hoenecke et al., 1992; Taiz and Zeiger, 1998). Moreover, changes in irradiance wavelengths can cause changes in the chlorophyll $a / b$ ratio (Walters and Horton, 1995), chlorophyll biosynthesis and action spectrum (Anstis and Northcot, 1974; French, 1991; Koski et al., 1951; Ogawa et al., 1973; Virgin, 1993), $\beta$-carotene biosynthesis (Ogawa et al., 1973), and decreases in chlorophyll $b$ under ultraviolet B light (Taiz and Zeiger, 1998).

Research has been performed to test the impact of light from LED lamps in several specific wavelengths, notably far-red, red, blue, and ultraviolet (Dougher and Bugbee, 2001; Okamoto et al., 1997; Yanagi et al., 1996). More recently, brighter diodes enabled their use as a potential replacement for traditional HPS systems in the 600- to $1000-\mathrm{W}$ category of lamps (Steranka et al., 2002). Claims of $50 \%$ energy savings for similar biomass yields are now common in the marketplace (Craford, 2005). The aim of this study was to examine if LED lamps can produce similar biomass and phytochemical levels compared with HPS lamps at reduced energy cost for lettuce grown in a hydroponics setup.

\section{Materials and Methods}

\section{Lettuce plant culture}

The Boston head lettuce (Lactuca sativa var. capitata) was provided by Hydroserre Mirabel (Mirabel, Quebec, Canada; lat. $45^{\circ} 39^{\prime} \mathrm{N}$ ). Lettuce plants were cultured and germinated according to HydroSerre Mirabel proprietary methods within a floating bed hydroponic system. After the initial transplant in the experimental block, plants were grown under light treatments for $28 \mathrm{~d}$.

\section{Test installation}

The experiment was conducted in a greenhouse (north-south orientation) in a central bay with no direct temperature control of the hydroponic water (Fig. 1). The first replication began $18 \mathrm{Feb}$. and the second $25 \mathrm{Mar}$. 2010. Each treatment section (plot) was at least $8.5 \mathrm{~m} \times 8.5 \mathrm{~m}$ and consisted of at least 1100 lettuce plants on floating trays per plot. The floating trays were $\approx 1.37 \mathrm{~m} \times 0.76 \mathrm{~m}$ and held 18 lettuce plants each. Spacing between plots were at least $8.5 \mathrm{~m}$ with no artificial lighting used in those buffer spaces and was determined based on the physical constrains 
of the greenhouse. No plot was within $8.5 \mathrm{~m}$ of the end of the pool (Fig. 2). Neighboring light pollution was limited by using shading cloths on the sides of the experimental bays (Fig. 1). Sensors were calibrated for solar irradiance before being installed in the experimental plots (MQ-200; Apogee Instruments, Logan, UT; S-LIB-M003 and S-LIA-M003; Hobo, Bourne, MA). As a result of the limitation of the radiation sensors to accurately measure artificial lighting above $650 \mathrm{~nm}$ (LED and HPS), a spectroradiometer (PS-100; Apogee Instruments) was used to calculate full spectrum irradiance (during the dark cycle) and provide correction factors for the irradiance provided by the artificial lights during both the light mapping and experimental period. Data loggers (U30 remote monitoring system; Hobo) and surface temperature sensors ( $\mathrm{S}$ TMB-002; Hobo) were laid on top of the floating trays to cause minimum shading to neighboring lettuces. The placement of LED lamps (TI-SL600; LED Innovation Design, Terrebonne, Quebec, Canada; Fig. 3) was selected in function of an effective radius of $1.27 \mathrm{~m}$ per lamp. The TI-SL600 array consists of LEDs from Philips Luxeon $(640,450$, and cool white; San Jose, CA) and Edison Opto (400 and 735; New Taipei City, Taiwan). Twenty-four LED lamps were used on each plot. The HPS plots (ballast: 71A85F5; Philips Advance, Amsterdam, Netherlands; bulb: LU600X0PSLT40 General Electric, Fairfield, CT) had 18 lamps spaced $\approx 1.83 \mathrm{~m}$ from each other, whereas the regular HPS plot had only four lamps each spaced to cover the plot. The control plot had no lamps.

\section{Experimental design}

The experimental design was a randomized complete block with sub blocks consisting of four light treatments [HPS, LED, regular greenhouse HPS level (regular), and no supplemental artificial light (control)] with two spatial replications for the HPS and LED light treatments (Fig. 2). This experimental arrangement was replicated for two lettuce production cycles. The lack of spatial replication of the HPS regular and control was the result of limitation in the size of the greenhouse bay and research focus on LED and HPS lighting systems. The light treatments were applied for $2 \mathrm{~h}$ before sunset and $8.5 \mathrm{~h}$ after sunset to extend the photoperiod to $18 \mathrm{~h}$ per day. Subblocks were randomly assigned at the beginning of both experimental replications. A total of 10 plants was randomly harvested from each treatment subblock at four different times during the experiment (Days 7, 14, 21, 28). Plants were randomly selected from each treatment and replication but the first three rows of plants on the edge were excluded to remove the edge effect. As a result of the large number of plants in the experimental area, no plants were ever harvested adjacent to a previously harvested plant. Sixty plants were harvested during each harvest time across all treatments.

\section{Experimental measurements}

Three light maps based on equally spaced grids of treatment areas consisting of $6 \times 6$

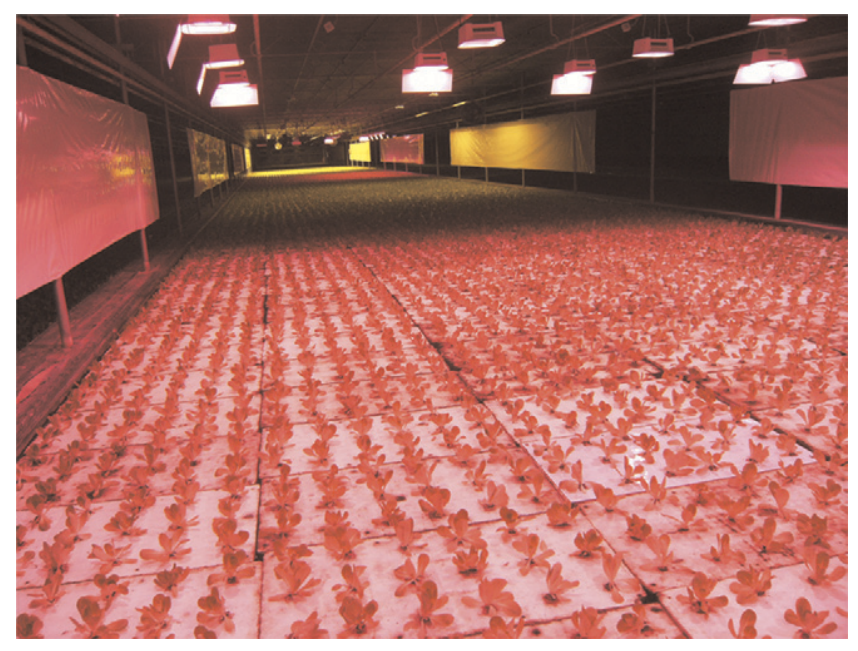

Fig. 1. Front view of experimental setup at night. Floating trays with lettuce plants and side drop cloths. View of the light-emitting diode (LED) treatment.

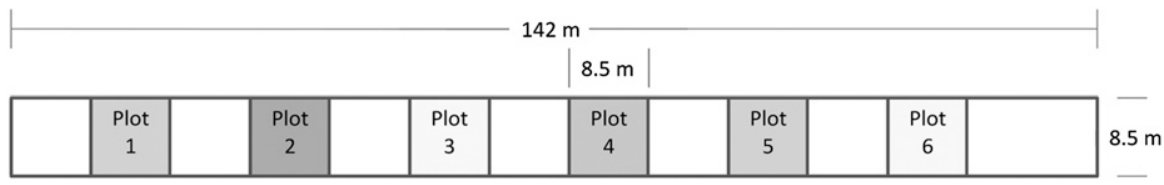

Fig. 2. Layout of the treatment plots within a single bay of the greenhouse. Plot 1: HPS; Plot 2: LED; Plot 3: regular HPS for Replication 1 and control for Replication 2; Plot 4: LED; Plot 5: HPS; Plot 6: control for Replication 1 and Regular HPS for Replication 2. Each plot was $8.5 \mathrm{~m} \times 8.5 \mathrm{~m}$ with at least $8.5 \mathrm{~m}$ between plots and between the plots and the end of the bay. HPS = high-pressure sodium; LED = lightemitting diode.

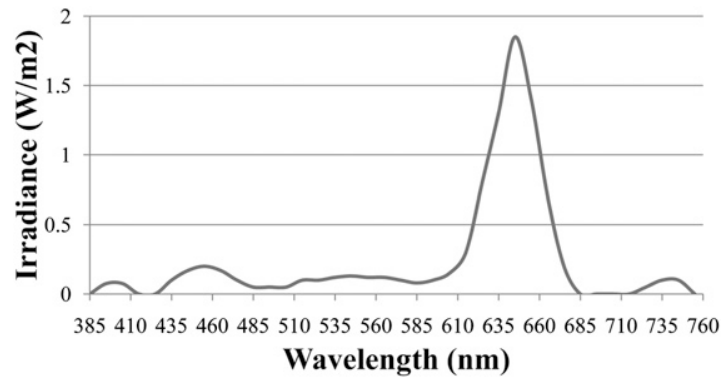

Fig. 3. Light irradiance from Smart Lamp TI-SL600. Irradiance from $400 \mathrm{~nm}$ to $700 \mathrm{~nm}$ is $78 \mathrm{~W} \cdot \mathrm{m}^{-2}$. Data courtesy of LED Innovation Design, Terrebonne, Quebec, Canada.

sample points were measured with a light sensor (MQ-200; Apogee Instruments, Logan, UT) to provide photosynthetically active radiation measurements. The light maps were completed at the beginning of the first experimental replication, at the beginning of the second replication, and at the end of the second replication. These light maps were performed after sunset and at canopy level. Irradiance was measured with pyranometers (S-LIB-M003; Hobo) and quantum sensors (S-LIA-M003; Hobo) connected to data loggers recording data for every minute during the entire experimental replication. Data loggers were installed on each subblock with a second quantum sensor per data logger. These sensors were placed randomly on the subblock and were mounted at the leaf canopy level. Additional temperature (S-TMB-002; Hobo) and relative humidity (S-THB-008; Hobo) sensors logged the surface temperature, air temperature, and relative humidity on all blocks and the water temperature was measured at the control block (Table 1).

\section{Lettuce harvest method}

At sampling time, fresh mass of individual plants and sum of 10 plant roots were measured. Plant and root tissues were then individually labeled, transported, and dried at Macdonald Campus, McGill University according to the ASABE standard (2007). Drying temperature was between 80 and $95{ }^{\circ} \mathrm{C}$ and duration of drying was no less than $72 \mathrm{~h}$ until a stable mass was attained. Plant tissues were weighed again after drying to record dry biomass.

\section{Lettuce carotenoid and chlorophyll determination}

Extraction. All leaf tissue samples were frozen before lyophilization (Gamma 1-16 
LSC; Martin Christ, MBI, Kirkland, Quebec, Canada). Pigments were extracted from freezedried tissues according to Kopsell et al. (2004) and analyzed according to Kopsell et al. (2007). A 0.1 -g tissue subsample was re-hydrated with $0.8 \mathrm{~mL}$ of ultrapure $\mathrm{H}_{2} \mathrm{O}$ for $20 \mathrm{~min}$. After incubation, $0.8 \mathrm{~mL}$ of the internal standard ethyl- $8^{\prime}$-apo- $\beta$-caroten- $8^{\prime}$-oate (Sigma Chemical Co., St. Louis, MO) was added to determine extraction efficiency. The addition of $2.5 \mathrm{~mL}$ of tetrahydrofuran (THF) was performed after sample hydration. The sample was then homogenized in a Potter-Elvehjem (Kontes, Vineland, NJ) tissue grinding tube using a pestle attached to a drill press set at $540 \mathrm{rpm}$. During homogenization, the tube was immersed in ice to dissipate heat. The tube was then placed into a clinical centrifuge for $3 \mathrm{~min}$ at $500 \mathrm{~g}_{\mathrm{n}}$. The supernatant was removed and the sample pellet was re-suspended in $2 \mathrm{~mL} \mathrm{THF}$ and homogenized again with the same extraction technique. The procedure was repeated for a total of four extractions to obtain a colorless supernatant. The combined supernatants were reduced to $0.5 \mathrm{~mL}$ under a stream of nitrogen gas (N-EVAP 111; Organomation Inc., Berlin, MA) and brought up to a final volume of $5 \mathrm{~mL}$ with methanol $(\mathrm{MeOH})$. A 2-mL aliquot was filtered through a $0.2-\mu \mathrm{m}$ polytetrafluoroethylene filter (Model Econofilter PTFE 25/20; Agilent Technologies, Wilmington, DE) before high-performance liquid chromatography (HPLC) analysis.

High-performance liquid chromatography analysis. High-performance liquid chromatography separation parameters and pigment quantification followed procedures of Kopsell et al. (2007). An Agilent 1200 series HPLC with a photodiode array detector (Agilent Technologies, Palo Alto, CA) was used for pigment separation. The column used was a $250 \mathrm{~mm} \times 4.6 \mathrm{~mm}$ inner diameter, $5-\mu \mathrm{m}$ analytical scale polymeric $\mathrm{RP}^{-\mathrm{C}_{30}}$ with a $10 \mathrm{~mm} \times 4.0 \mathrm{~mm}$ inner diameter guard cartridge and holder (ProntoSIL; MAC-MOD Analytical Inc., Chadds Ford, PA), which allowed for effective separation of chemically similar carotenoid compounds. The column was maintained at $30{ }^{\circ} \mathrm{C}$ using a thermostatted column compartment. All separations were achieved isocratically using a binary mobile phase of $11 \%$ methyl tert-butyl ethanol, $88.9 \% \mathrm{MeOH}$, and $0.1 \%$ triethylamine $(\mathrm{v} / \mathrm{v} / \mathrm{v})$. The flow rate was $1.0 \mathrm{~mL} / \mathrm{min}$ with a run time of $53 \mathrm{~min}$ followed by a $2-\mathrm{min}$ equilibration before the next injection. Eluted compounds from a $10-\mu \mathrm{L}$ injection loop were detected at $453 \mathrm{~nm}$ [carotenoids, chlorophyll $b(\mathrm{Chl} b)$, internal standard] and $652 \mathrm{~nm}$ [chlorophyll $a(\mathrm{Chl} a)$ ] and data were collected, recorded, and integrated using ChemStation Software (Agilent Technologies). Peak assignment for individual pigments was performed by comparing retention times and line spectra obtained from photodiode array detection using authentic external standards (ChromaDex Inc., Irvine, CA). Every effort was made to reduce any effects of light and/or thermal degradation of lettuce leaf tissue pigments during extraction and HPLC analysis. Extractions were carried out under reduced light because the laboratory had no windows and only fluorescent lighting (low light intensity and limited wavelengths below $400 \mathrm{~nm}$ ). In addition, exposure to all light was reduced during extraction by placing solutions under cover in ice baths. Samples were also filtered into amber HPLC vials that further reduce light and protected when run on the HPLC by a tinted shield covering the autosampler.

\section{Energy measurement}

The energy measurements were done using a setup allowing the circuit to be opened and two multimeters to be used simultaneously for current and voltage readings. For voltage readings, a multimeter MTP 2325 (Montreal, CA) at $700 \mathrm{~V} \mathrm{AC}$ scale was used at a $1-\mathrm{V}$ resolution. The precision is rated at $1.2 \%$ and input impedance is $10 \mathrm{M} \Omega$. For current readings, a multimeter Fluke 179 (Calgary, CA) was used. The setting was Amps $\mathrm{AC}$, automatic scale, resolution of $0.001 \mathrm{~A}$ between 1 and 6 amps, and a precision of $1.5 \%$ at $37 \mathrm{mV} / \mathrm{A}$.

\section{Statistical analysis}

Plant productivity was calculated as a function of total light (natural and supplemental) measured by wet and dry plant mass in grams vs. light in moles per meter ${ }^{2}$. Normalized plant production values assumed equal plant biomass production from natural and artificial light and calculated production rates based on the percentage of supplemental light vs. total light (dry mass produced by artificial lighting $=$ dry mass per $\mathrm{m}^{2} *$ sunlight/ total light). Statistical analysis was performed using SPSS (Somers, NY). Analysis of variance was done with treatment as random factors, whereas fixed location and samples were random factors. Least significant difference $(P<0.05)$ was determined according to Tukey-Kramer multiple range test.

\section{Results}

Environmental data. Air temperature at canopy height was a daily average of 12.5 $(\mathrm{SD} \pm 5.2)^{\circ} \mathrm{C}$. The average water temperature was 15.5 (SD \pm 0.5$){ }^{\circ} \mathrm{C}$. No significant difference was measured in temperatures between replications (Table 1). The greenhouse section was outfitted with two horizontal airflow fans that operated continuously during the day to improve mixing of the greenhouse air. Total irradiance levels were measured for both replications as an average of both quantum sensors (Table 1). The ratios of supplemental light to total light (natural + supplemental) was $21.0 \%$ for the HPS, $11.3 \%$ for the LED, $4.5 \%$ for the regular HPS, and $0.7 \%$ for the control.

Lettuce biomass yield. There was no significant difference in fresh weight per plant or dry biomass per plant among the HPS, LED, or greenhouse HPS level (regular) light treatments (Figs. 4 and 5). By the fourth week of production, the HPS, LED, and regular light treatments produced fresh lettuce mass values of $114.3 \pm 54.2 \mathrm{~g}, 94.3 \pm 46.5 \mathrm{~g}$, and $102.5 \pm$ $28.7 \mathrm{~g}$, respectively. Lettuce dry mass values by the fourth week of production for the HPS, LED, and regular light treatments were $6.17 \pm$ $2.05 \mathrm{~g}, 5.82 \pm 2.50 \mathrm{~g}$, and $5.70 \pm 2.04 \mathrm{~g}$, respectively. Lettuce plants subjected to no supplemental artificial lighting (control) produced $82.3 \pm 38.2 \mathrm{~g}$ for fresh biomass and $4.78 \pm 1.83 \mathrm{~g}$ for dry biomass by the fourth week of production.

LED, HPS, and HPS regular light treatment achieved similar wet plant productivity of $7.21 \mathrm{~g} \cdot \mathrm{mol}^{-1} \cdot \mathrm{m}^{-2}$ and $8.18 \mathrm{~g} \cdot \mathrm{mol}^{-1} \cdot \mathrm{m}^{-2}$, and $8.85 \mathrm{~g} \cdot \mathrm{mol}^{-1} \cdot \mathrm{m}^{-2}$ respectively, whereas the

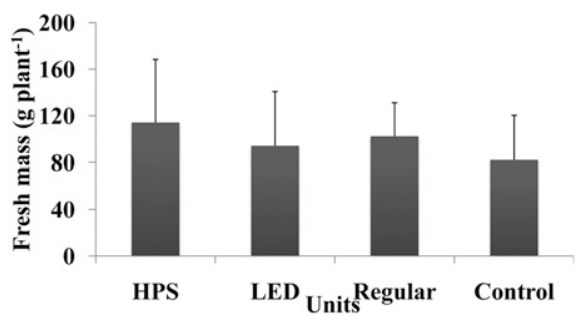

Fig. 4. Final average plant fresh biomass for Boston lettuce (Lactuca sativa var. capitata) grown hydroponically under different treatments in a controlled environment. HPS $=$ high-pressure sodium; LED = light-emitting diode; Regular = regular greenhouse HPS levels; Control = no supplemental artificial lighting. Harvest of 10 plants from each treatment averaged over two replications with SD bars. 


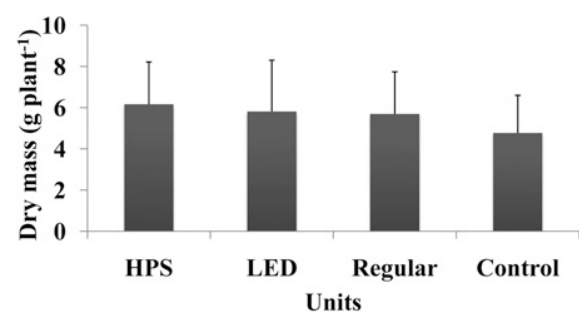

Fig. 5. Final average plant dry biomass for Boston lettuce (Lactuca sativa var. capitata) grown hydroponically under different treatments in a controlled environment. HPS = high-pressure sodium; LED = light-emitting diode; Regular = regular greenhouse HPS levels; Control = no supplemental artificial lighting. Harvest of 10 plants from each treatment averaged over two replications with SD bars.

control was different at $5.88 \mathrm{~g} \cdot \mathrm{mol}^{-1} \cdot \mathrm{m}^{-2}$. Dry plant productivity values are typically more stable than wet plant productivity values (Lefsrud et al., 2008b) as a result of yield being directly impacted by photosynthetic production and less on water content in the leaves. This dry mass productivity provides a better understanding of the effect of light on plant growth. The results for LED and HPS light treatments are similar with dry plant productivity of $0.46 \mathrm{~g} \cdot \mathrm{mol}^{-1} \cdot \mathrm{m}^{-2}$ for HPS and $0.45 \mathrm{~g} \cdot \mathrm{mol}^{-1} \cdot \mathrm{m}^{-2}$ for LED for the both experimental replications (Table 2). This may indicate both light treatments as well as HPS regular at $0.49 \mathrm{~g} \cdot \mathrm{mol}^{-1} \cdot \mathrm{m}^{-2}$ have similar effects on the growth of Boston lettuce.

Lighting energy results. The average LED lamp consumes $319 \mathrm{~W}$ of electricity, whereas a HPS lamp consumes $642 \mathrm{~W}$ (Table 3 ). There were 24 LED lamps per plot; therefore, the energy demand for the LED lamps in the chosen configuration, on an area basis, is $81.8 \mathrm{~W} \cdot \mathrm{m}^{-2}$. There were 18 HPS lamps per plot translating into an energy input of $123.5 \mathrm{~W} \cdot \mathrm{m}^{-2}$. The regular HPS light treatment required only four lamps for an energy input of $27.4 \mathrm{~W} \cdot \mathrm{m}^{-2}$. There were no lamps in the control and the artificial light reported was from light bleed from distant supplemental lighting. The average biomass production at the end of the treatments was statistically identical and according to our experimental setup; however, the LED lamps provide energy savings of at least $33.8 \%$ over the HPS treatment, whereas the regular HPS provided an energy savings of $77.8 \%$ (Table 3 ).

Lettuce phytochemicals. No significant differences were found in pigment phytochemical concentrations among the LED, HPS, regular HPS, or control light treatments with the exception of violaxanthin at the $P<0.1$ level but not at the $P<0.05$ level (Table 4). For violaxanthin, the control plants had the highest concentration $[4.39 \mathrm{mg} / 100 \mathrm{~g}$ fresh mass (FM)] and the LED treatment plants (2.22 mg/100 g FM) produced significantly less violaxanthin than control. For the remaining pigments, the control light treatment had the highest measured concentration of antheraxantin $(3.27 \mathrm{mg} / 100 \mathrm{~g} \mathrm{FM}), \beta$-carotene (5.53 mg/100 g FM), chlorophyll a (16.2 mg/
100 g FM), chlorophyll b (12.3 mg/100 g FM), lutein $(6.9 \mathrm{mg} / 100 \mathrm{~g} \mathrm{FM})$, and neoxanthin (2.09 mg/100 g FM). The second highest amounts of phytochemicals were observed in the regular HPS treatment.

\section{Discussion}

Both LED and HPS light treatments were significantly similar in fresh and dry biomass production for lettuce. The LED lamps did not appear to have any negative visual quality impact. The HPS treatment plants were slightly larger (not statistically significant) in fresh biomass compared with the LED plants. However, earlier research has shown increased yields when using LEDs within growth chambers (Johkan et al., 2010). Johkan et al. (2010) reported that at $17 \mathrm{~d}$ after sowing, the leaf area and shoot fresh weight of lettuce seedlings treated with red light increased by $33 \%$ and $25 \%$, respectively, and the dry biomass of the shoots and roots of the lettuce seedlings treated with blue-containing LED lights increased by greater than $29 \%$ and greater than $83 \%$ compared with seedlings grown under a white fluorescent lamp. At $45 \mathrm{~d}$ after sowing, higher leaf areas and fresh biomass were obtained in lettuce plants treated with blue-containing LED lights. One

Table 2. Dry and wet plant productivity as biomass produced per mole of light for Boston lettuce (Lactuca sativa var. capitata) grown hydroponically in a controlled environment under different light treatments. $^{\mathrm{z}}$

\begin{tabular}{lcccc}
\hline Dry mass per & $\begin{array}{c}\text { Dry mass produced by } \\
\text { Unit }^{\mathrm{y}}\end{array}$ & $\begin{array}{c}\text { Dry mass per mole of } \\
\text { artificial lighting } \\
\left(\mathrm{g} \cdot \mathrm{mol}^{-1} \cdot \mathrm{m}^{-2}\right)\end{array}$ & $\begin{array}{c}\text { Wet mass per mole of } \\
\text { artificial lighting } \\
\left(\mathrm{g} \cdot \mathrm{mol}^{-1} \cdot \mathrm{m}^{-2}\right)\end{array}$ \\
\hline HPS & $151.4 \pm 49.7 \mathrm{a}$ & $32.08 \pm 10.4 \mathrm{a}$ & $0.46 \pm 0.15$ & $8.18 \pm 3.87$ \\
LED & $141.8 \pm 60.5 \mathrm{a}$ & $16.23 \pm 6.9 \mathrm{~b}$ & $0.45 \pm 0.19$ & $7.21 \pm 3.56$ \\
Regular & $138.1 \pm 49.6 \mathrm{a}$ & $6.22 \pm 2.2 \mathrm{c}$ & $0.49 \pm 0.17$ & $8.85 \pm 2.48$ \\
Control & $116.3 \pm 44.4 \mathrm{~b}$ & $0.81 \pm 0.3 \mathrm{~d}$ & $0.32 \pm 0.13$ & $5.88 \pm 2.73$ \\
\multicolumn{2}{l}{ Significance } \\
\end{tabular}

${ }^{\mathrm{z}}$ Data were means of two replications after $28 \mathrm{~d}$ treatment.

${ }^{\text {y } H P S}=$ high-pressure sodium; LED = light-emitting diode; Regular = regular greenhouse HPS levels; Control $=$ no supplemental artificial lighting.

${ }^{\mathrm{x}}$ Mass produced by artificial light is based on the biomass produced per individual mole of light divided by the percentage of artificial light (dry mass produced by artificial lighting $=$ dry mass per $\mathrm{m}^{2} *$ sunlight/total light).

${ }^{\text {w}}$ Least significant difference $(P<0.05)$ was determined according to Tukey-Kramer multiple range test. Values followed by the same letter in the same column do not differ at the $5 \%$ significance level.

NS and *Nonsignificant and significant, respectively.

Table 3. Power consumption for producing Boston lettuce (Lactuca sativa var. capitata) grown hydroponically in a controlled environment under different light treatments.

\begin{tabular}{lccccc}
\hline & $\begin{array}{c}\text { Power } \\
\text { Unit }^{z}\end{array}$ & $\begin{array}{c}\text { Number } \\
\text { of lamp } \\
\text { consumption }\end{array}$ & $\begin{array}{c}\text { Power } \\
\text { consumption } \\
\text { per plot }(\mathrm{W})\end{array}$ & $\begin{array}{c}\text { Power } \\
\text { consumption per } \\
\text { meter }^{2}\left(\mathrm{~W} \cdot \mathrm{m}^{-2}\right)\end{array}$ & $\begin{array}{c}\text { Power savings } \\
\text { compared with } \\
\text { HPS }(\%)\end{array}$ \\
\hline HPS & 642 & 18 & 11,556 & 123.5 & 0.0 \\
LED & 319 & 24 & 7,656 & 81.8 & 33.8 \\
Regular & 642 & 4 & 2,568 & 27.4 & 77.8 \\
Control & 0 & 0 & 0 & 0.0 & N/A \\
\hline
\end{tabular}

${ }^{\mathrm{z}} \mathrm{HPS}=$ high-pressure sodium; LED = light-emitting diode; Regular = regular greenhouse HPS levels; Control $=$ no supplemental artificial lighting.

y Power consumption was measured twice during the experiments with no difference in average power consumption.

$\mathrm{N} / \mathrm{A}=$ not applicable.

Table 4. Mean phytochemicals (mg/100 $\mathrm{g}$ fresh weight) concentrations $\mathrm{z}^{\mathrm{z}}$ in the leaf tissues of Boston lettuce (Lactuca sativa var. capitata) grown hydroponically in a controlled environment under different light treatments. ${ }^{\mathrm{y}}$

\begin{tabular}{lrrrrrrl}
\hline \multicolumn{7}{c}{ Phytochemicals $(\mathrm{mg} / 100 \mathrm{~g} \mathrm{FM})^{\mathrm{z}}$} \\
\hline \multicolumn{2}{c}{ Antheraxanthin } & $\beta$-carotene & Chl $a$ & \multicolumn{1}{c}{ Chl $b$} & Lutein & Neoxantin & Violaxanthin \\
\hline HPS & $2.53 \pm 0.73$ & $4.06 \pm 0.86$ & $12.3 \pm 2.9$ & $9.6 \pm 2.4$ & $5.2 \pm 1.4$ & $1.60 \pm 0.54$ & $3.06 \pm 0.69 \mathrm{a}, \mathrm{b}$ \\
LED & $2.22 \pm 0.82$ & $3.33 \pm 1.32$ & $10.2 \pm 4.6$ & $8.1 \pm 4.1$ & $4.4 \pm 1.7$ & $1.32 \pm 0.61$ & $2.22 \pm 0.79 \mathrm{a}$ \\
Regular & $2.88 \pm 0.64$ & $4.93 \pm 0.85$ & $14.2 \pm 2.6$ & $11.2 \pm 2.1$ & $6.1 \pm 1.0$ & $1.87 \pm 0.04$ & $3.67 \pm 0.15 \mathrm{a}, \mathrm{b}$ \\
Control & $3.27 \pm 0.34$ & $5.53 \pm 0.34$ & $16.2 \pm 0.4$ & $12.3 \pm 0.5$ & $6.9 \pm 0.1$ & $2.09 \pm 0.29$ & $4.39 \pm 0.16 \mathrm{~b}$ \\
Significance &
\end{tabular}

Significance $^{\mathrm{x}}(P<0.10)$
NS
NS NS
NS NS

${ }^{\mathrm{z}} \mathrm{Chl} \mathrm{a}=$ chlorophyll $\mathrm{a} ; \mathrm{Chl} \mathrm{b}=$ chlorophyll b; FM = fresh weight, HPS = high-pressure sodium; LED = light-emitting diode; Regular = regular greenhouse HPS levels; Control = no supplemental artificial lighting.

${ }^{\mathrm{y}}$ Mean composition of sampled leaf tissue of four replications.

${ }^{\mathrm{x}}$ Least significant difference $(P<0.05)$ was determined according to Tukey-Kramer multiple range test. Values followed by the same letter in the same column do not differ at the $10 \%$ significance level. NS and *Nonsignificant and significant, respectively. 
possible explanation for our lack of significance in yield from this study was that other environmental growth conditions within the greenhouse (temperature, humidity, carbon dioxide, shadecloth, and the natural light) had a larger impact on production than the supplemental light. The research by Johkan et al. (2010) was performed in a growth chamber limiting the external influence of solar radiation. Multiple samples per plot were harvested in lines parallel to the shading cloth. In fact, a partial shading mechanism (shadecloth) was used to reduce the incoming solar radiation during peak hours. This may have affected narrow strips of plants and created a localized effect as demonstrated by Shinohara and Suzuki (1981) in an experiment designed to show the impact of shading on biomass production.

Variability in the measured solar radiation was noticed between the different treatments but was not statistically significant (Table 1). The radiation values presented were an average of four sensors per run for the LED and HPS treatments and two sensors per run for the regular HPS and control. The variability in measured sunlight was a result of the random physical placement of the sensors, location of the treatments in the greenhouse, and shading effect from overhead equipment (shadecloth, structural members, fans, and lights). As expected, the control treatment had the highest average available solar radiation resulting from less overhead lights, but this was not statistically significant.

The LED lamps used $\approx 66 \%$ of the energy of the optimal HPS lamps, whereas the regular HPS schedule used $\approx 22 \%$ of the equivalent optimal HPS plot or $33.5 \%$ of the LED energy use. One watt of LED light produced 0.019 $\mathrm{g} \cdot \mathrm{m}^{-2}$ of dry matter, whereas $1 \mathrm{~W}$ of HPS light produced $0.013 \mathrm{~g} \cdot \mathrm{m}^{-2}$ of dry matter. It is important to note the different number of lamps between both lighting technologies. In fact, an LED lamp is estimated to use $\approx 50 \%$ of the energy of a HPS lamp. Concretely, this means that although the lamp density must by higher to maintain acceptable photon flux, LED lamps can produce significant energy savings over time, which may translate into economic incentives that would increase adoption rates among producers (Papadopoulos and Gosselin, 2007).

We measured the concentrations of many photosynthetically important phytochemicals in the lettuce plants to determine the impacts of the different lighting technologies on product quality. The control plants produced the highest concentrations of pigment phytochemicals in the lettuce, whereas the regular HPS, HPS, and LED light treatments were all statistically similar in concentrations. Violaxanthin is a good indicator of light conditions (Demmig-Adams and Adams, 1992; Eskling et al., 1997). However, concentrations of xanthophylls vary daily and are also affected by both cold and hot temperatures, salinity, nutrient, and other stresses (Demmig-Adams and Adams, 1992). The HPS treatments produced more violaxanthin than the LED treatment, and previous research by Lefsrud et al. (2008a) reported that wavelength of light can have an impact on the accumulation of kale plant pigments. Yasuhiro et al. (2002) reported that by controlling the lighting cycles of white LEDs, lettuce plants could be stressed to increase phytochemical production. White LEDs are currently less efficient than HPS but should improve with time and this could potentially increase energy savings while producing higher nutrient content. More research is necessary in this area to verify if optimized wavelength pulses are the next stage of controlled environment biomass production.

Johkan et al. (2010) reported that the total chlorophyll content in lettuce plants treated with blue-containing and red lights were less than that of lettuce plants treated with fluorescent lamps, but the chlorophyll a/b ratio and carotenoid content increased under bluecontaining LED lights. Polyphenol content and the total antioxidant status were greater in lettuce seedlings treated with blue-containing LED lights than in those treated with white fluorescent lamp at $17 \mathrm{~d}$ after seeding (DAS). The higher polyphenol content and total antioxidant status in lettuce seedlings at 17 DAS decreased in lettuce plants at 45 DAS. Likewise, Stutte et al. (2009) reported that LED lighting induced a number of effects on morphology that increased both accumulation of bioprotective compounds (anthocyanins) and total yield. However, our results did not measure any change in accumulation of chlorophyll or other carotenoids caused by the LEDs with the exception of violaxanthin.

The results of this study show that if the grower wants to maximize production of plant biomass, the regular treatment is equal to both the LED and HPS treatments and provides a significant energy savings. Based on our results, the regular HPS, HPS, and LED all resulted in the production of statistically identical production. If the grower wants to maximize profitability at the expense of maximal levels of production, it is recommended to use limited supplemental light treatments based on transient weather conditions. This choice should be based on economic factors such as initial investment cost, return on investment, and market conditions (Carrier, 1999).

In conclusion, this experiment has shown that both HPS and LED light treatments have the potential to produce adequate Boston lettuce. Although HPS produces more moles of light when compared with LED lights, the impact on dry plant biomass production is very limited yet still important. Clear gains can be made using some levels of supplemental light to prolong the growing photoperiod. Therefore, varying levels of additional light intensity can be explored to provide the best economic scenario with little fluctuation expected in final plant mass productivity. This should be of particular interest to producers subjected to tiered electrical costs based on time of the day or other similar constraints. According to the experimental setup, the LED lamps produce statistically the same amount of dry matter as the HPS lamps and regular
HPS while consuming $33.8 \%$ less electricity than the HPS lamps, whereas the regular HPS provided an energy savings of $77.8 \%$ over the HPS lamps. These are encouraging results for the LED technology because the reduced electricity costs do not impact the final crop yields.

\section{Literature Cited}

Anstis, P.J.P. and D.H. Northcot. 1974. Chlorophyll accumulation by callus tissues of glycinemax. Planta 116:105-108.

Bourget, C.M. 2008. An introduction to lightemitting diodes. HortScience 43:1944-1946.

Brown, C.S., A.C. Schuerger, and J.C. Sager. 1995. Growth and photomorphogenesis of pepper plants under red light-emitting diodes with supplemental blue or far-red lighting. J. Amer. Soc. Hort. Sci. 120:808-813.

Carrier, A. 1999. Status of the greenhouse industry in Québec, Canada. Acta Hort. 481:743747.

Craford, M.G. 2005. LEDs for solid state lighting and other emerging applications: Status, trends, and challenges. SPIE Proc. 5941:1-10.

Demmig-Adams, B. and W.W.I.I.I. Adams. 1992 Photoprotection and other responses of plants to high light stress. Annu. Rev. Plant Physiol. Plant Mol. Biol. 43:599-626.

Dougher, T.A.O. and B. Bugbee. 2001. Differences in the response of wheat, soybean and lettuce to reduced blue radiation. Photochem. Photobiol. 73:199-207.

Eskling, M., P.O. Arvidsson, and H.E. Åkerlund. 1997. The xanthophyll cycle, its regulation and components. Physiol. Plant. 100:806-816.

French, C.S. 1991. Action spectra of photosystems I and II scaled by comparison of their sums with absorption spectra of photosynthetic plants. Photosynthetica 25:67-74.

Heraut-Bron, V., C. Robin, C. Varlet-Grancher, and A. Guckert. 2001. Phytochrome mediated effects on leaves of white clover: Consequences for light interception by the plant under competition for light. Ann. Bot. (Lond.) 88:737-743

Hoenecke, M.E., R.J. Bula, and T.W. Tibbitts. 1992. Importance of 'Blue' photon levels for lettuce seedlings grown under red-light-emitting diodes. HortScience 27:427-430.

Johkan, M., K. Shoji, F. Goto, S. Hashida, and T. Yoshihara. 2010. Blue light-emitting diode light irradiation of seedlings improves seedling quality and growth after transplanting in red leaf lettuce. HortScience 45:1809-1814.

Kopsell, D.A., T.C. Barickman, C.E. Sams, and J.S. McElroy. 2007. Influence of nitrogen and sulfur on biomass and carotenoid and glucosinolate concentrations in watercress (Nasturtium officinale R. Br.). J. Agr. Food Chem. 55:10628 10634.

Kopsell, D.A., D.E. Kopsell, M.G. Lefsrud, J. CurranCelentano, and L. Dukach. 2004. Variation in lutein, B-carotene, and chlorophyll concentrations among Brassica oleracea cultigens and seasons. HortScience 39:361-364

Koski, V.M., C.S. French, and J.H.C. Smith. 1951 The action spectrum for the transformation of protochlorophyll to chlorophyll a in normal and albino corn seedlings. Arch. Biochem. Biophys. 31:1-17.

Lefsrud, M.G., D.A. Kopsell, and C.E. Sams. 2008a. Wavelengths from adjustable light-emitting diodes affect secondary metabolites in kale. HortScience 43:2243-2244.

Lefsrud, M.G., D.A. Kopsell, J. Wills, Jr., C. Sams, and A.J. Both. 2008b. Dry matter content and 
stability of carotenoids in kale and spinach during drying. HortScience 43:1731-1736.

McAvoy, R.J. 1984. The use of high pressure sodium lights in greenhouse tomato crop production. Acta Hort. 148:877-888.

Morrow, R.C. 2008. LED lighting in horticulture. HortScience 43:1947-1950.

Ogawa, T., Y. Inoue, M. Kitajima, and K. Shibata. 1973. Action spectra for biosynthesis of chlorophylls $\mathrm{a}$ and $\mathrm{b}$ and $\beta$-carotene. Photochem. Photobiol. 18:229-235.

Okamoto, K., T. Yanagi, and S. Kondo. 1997. Growth and morphogenesis of lettuce seedlings raised under different combinations of red and blue light. Acta Hort. 435:149-158.

Papadopoulos, A.P. and D.A. Demers. 2000. The Canadian greenhouse vegetable industry with special emphasis on artificial lighting. Acta Hort. 580:29-33.
Papadopoulos, A.P. and A. Gosselin. 2007. Greenhouse vegetable production in canada. Chron. Hort. 47:23-28.

Shinohara, Y. and Y. Suzuki. 1981. Effects of light and nutritional conditions on the ascorbic acid content of lettuce. J. Jpn. Soc. Hort. Sci. 239 246.

Steranka, F.M., J. Bhat, D. Collins, L. Cook, M.G. Craford, and R. Fletcher. 2002. High power LEDs-Technology status and market applications. Phys. Status Solidi 194:380388.

Stutte, G.W., S. Edney, and T. Skerritt. 2009. Photoregulation of bioprotectant content of red leaf lettuce with light-emitting diodes. HortScience 44:79-82.

Taiz, L. and E. Zeiger. 1998. Plant physiology. 2nd Ed. Sinauer Associates, Inc., Sunderland, MA
Tennessen, D.J., E.L. Singsaas, and T.D. Sharkey. 1994. Light-emitting diodes as a light source for photosynthesis research. Photosynth. Res. 39:85-92.

Virgin, H.I. 1993. Effectiveness of light of different wavelengths to induce chlorophyll biosynthesis in rapidly and slowly greening tissue. Physiol. Plant. 89:761-766.

Walters, R.G. and P. Horton. 1995. Acclimation of Arabidopsis thaliana to the light environment: Regulation of chloroplast composition. Planta 197:475-481.

Yanagi, T., K. Okamoto, and S. Takita. 1996. Effect of blue and red light intensity on photosynthetic rate of strawberry leaves. Acta Hort. 440:371376.

Yasuhiro, M., T. Masamoto, and Y. Takashi. 2002. Effects of pulsed white led light on the growth of lettuce. J. Soc. High Technol. Agr. 136-140. 